\title{
Trypanosoma (Schizotrypanum) dionisii: Effect of Various Agents on Attachment and Entry to Macrophages in vitro and on Morphogenesis
}

\author{
By J. R. BAKER AND A. J. LISTON \\ MRC Biochemical Parasitology Unit, Molteno Institute, Downing Street, \\ Cambridge $C B 2{ }_{3} E E$
}

(Received I I July I977)

\begin{abstract}
The attachment and entry of Trypanosoma dionisii to mouse peritoneal macrophages in vitro were studied. Both occurred to a similar extent whether parasites were alive or heat-killed, and whether macrophages were obtained from normal or immunized mice. Attachment occurred equally at 4 and $37^{\circ} \mathrm{C}$, but entry only occurred at the higher temperature. Neither was affected by pretreatment of parasites with active or inactivated complement. Entry, but not attachment, was inhibited by cytochalasin B; both were inhibited by trypsin. Immune mouse plasma (if inactivated) stimulated attachment but not entry (within $24 \mathrm{~h}$ ). It also stimulated intracellular replication of $T$. dionisii by multiple fission and subsequent differentiation (probably within macrophages) to small extracellular trypomastigotes. No extracellular parasite and only scanty intracellular forms survived $\mathrm{I} 20 \mathrm{~h}$ in cultures containing non-inactivated immune mouse plasma. It was concluded that attachment (in the absence of antibody) occurred to non-specific receptors in the macrophage membrane and was followed by phagocytosis of the parasites rather than their active penetration of the cell.
\end{abstract}

\section{INTRODUCTION}

Trypanosoma (Schizotrypanum) dionisii Bettencourt \& França, 1905 parasitizes bats (Pipistrellus pipistrellus) in Europe (including England), and develops in mouse peritoneal macrophages and other cell lines in vitro (Baker et al., 1972). It has been studied as a possible model for the behaviour of the pathogen $T$. (S.) cruzi (Baker, I976). Liston (1975) and Liston \& Baker (1977) observed that epimastigotes entered macrophages in vitro hind end first, whereas trypomastigotes entered with either pole foremost, and that entry seemed to be largely due to active phagocytosis by the host cell. This paper reports further studies on the parasite's entry to the host macrophage and its subsequent morphogenesis, including effects of temperature, complement, trypsin, cytochalasin B and immune plasma.

\section{METHODS}

Trypanosomes. The isolation and maintenance of stock $\mathbf{P} 3$ of $T$. dionisii, the preparation of clone no. 3 of that stock, and medium composition have been documented by Baker et al. (1972) and Baker, Liston \& Selden (1976). The term stock is used (instead of strain) to signify a population derived by serial passage from a primary isolation, without any implication of homogeneity or characterization. Stock P2 of $T$. dionisii was isolated from a $P$. pipistrellus of the same batch and has been maintained similarly. Either washed flagellates from I-day-old L4NHS cultures at $28{ }^{\circ} \mathrm{C}$ (about $95 \%$ live epimastigotes) or trypomastigotes prepared from older cultures (Baker et al., 1976) - sometimes with the omission of active complement treatment - were used at $5 \times 10^{5} \mathrm{ml}^{-1}$ as inocula for macrophage cultures. In some experiments, parasites were killed by immersion in a water bath at $50^{\circ} \mathrm{C}$ for $4 \mathrm{~min}$ before inoculation. 
Macrophages. Cultures of peritoneal macrophages from unstimulated male $\mathrm{P}(\mathrm{SD})$ mice (Animal Virus Research Institute, Pirbright, Surrey) were prepared and maintained at $37^{\circ} \mathrm{C}$ as described by Baker et al. (1972) in medium 199 (Wellcome, TC45) containing 20 mM-HEPES (Hopkin and Williams), approx. 5 mM-sodium bicarbonate [10 $\mathrm{ml} \mathrm{l}^{-1}$ of a $4 \cdot 4 \%(\mathrm{w} / \mathrm{v})$ solution; Wellcome, TC27], 200 i.u. penicillin $\mathrm{ml}^{-1}$ and $100 \mu \mathrm{g}$ streptomycin $\mathrm{ml}^{-1}$. After adjustment to $\mathrm{pH} 7 \cdot 2$ with approx. IO $\mathrm{M}$-sodium hydroxide solution, Io or $20 \%(\mathrm{v} / \mathrm{v})$ serum (heat-inactivated Wellcome calf serum no. I, CS 07 , or a mixture of this and murine plasma) was added and the medium was sterilized by membrane filtration (Millipore, $0.2 \mu \mathrm{m}$ pore diameter). Macrophages were harvested both from normal mice and from those immunized as described by Liston, Baker \& Selden (1977).

Cytochalasin B (ICI Ltd, distributed by Aldrich Chemical Company Inc., Milwaukee, Wisconsin 53233, U.S.A.; British agents, R. N. Emanuel Ltd, 264 Water Road, Wembley, Middlesex HAo IPY) was dissolved in dimethylsulphoxide (DMSO; BDH Ltd) at $5 \mathrm{mg} \mathrm{ml}^{-1}$ and the solution was diluted $\mathrm{I}$ : 1000 ( $\mathrm{v} / \mathrm{v}$ ) in medium 199 to give a final concentration of $5 \mu \mathrm{g} \mathrm{ml}^{-1}$. Peritoneal macrophages, collected as described above, were allowed to settle at $37^{\circ} \mathrm{C}$ in medium 199 without serum for about $24 \mathrm{~h}$. The medium was then removed and replaced by that containing cytochalasin B. Control cultures were similarly treated with medium 199 containing $0 . \mathrm{I} \%(\mathrm{v} / \mathrm{v}) \mathrm{DMSO}$. After $\mathrm{I}$ to $\mathrm{I} \cdot 5 \mathrm{~h}$ at $37^{\circ} \mathrm{C}$, this medium was removed and epimastigotes or trypomastigotes $\left(5 \times 10^{5} \mathrm{ml}^{-1}\right)$ were added, suspended in similar medium (containing either cytochalasin $\mathrm{B}$ and DMSO or DMSO alone) plus $20 \%(\mathrm{v} / \mathrm{v})$ heat-inactivated calf serum. After $\mathrm{I} \mathrm{h}$ at $37^{\circ} \mathrm{C}$, cultures were fixed and stained (Baker et al., 1972). In some experiments, the trypanosome suspension was removed and replaced by medium 199 plus serum and DMSO or cytochalasin B, without parasites, for a further 30 min at $37^{\circ} \mathrm{C}$ before fixation.

Trypsin (bovine pancreas type III; Sigma no. KT $27 \mathrm{BH}$ ) was dissolved in medium 199 without serum at $500 \mu \mathrm{g} \mathrm{ml}^{-1}$. Some macrophage cultures were treated with this solution for $30 \mathrm{~min}$ between their initial exposure to cytochalasin B or DMSO and the addition of medium containing trypanosomes (see above); others were treated with trypsin only. Before adding medium containing trypanosomes, the trypsin solution was washed off with medium 199 (without serum) containing ovomucoid trypsin inhibitor $\left(500 \mu \mathrm{g} \mathrm{ml}^{-1}\right.$; Sigma).

Complement was obtained as freeze-dried preserved guinea-pig serum (Wellcome, CToI) and reconstituted with distilled water to the equivalent of a $\mathrm{I}: \mathrm{Io}$ dilution of serum in isotonic saline. Trypomastigotes were normally treated with this dilution for $20 \mathrm{~min}$ at $37^{\circ} \mathrm{C}$ as part of their separation process (Baker et al., 1976). In some experiments, heat-inactivated complement $\left(56^{\circ} \mathrm{C}, 30 \mathrm{~min}\right)$ was used instead, and in one experiment, epimastigotes were similarly treated with heat-inactivated complement. All trypanosomes were subsequently resuspended in medium 199 plus serum (as described) before being added to macrophage cultures.

Figs I-I4. Histograms showing results of in vitro experiments using Trypanosoma dionisii (clone 3 of stock P3, except for experiments $244,248,254$ and B6 in which uncloned stock P2 was used) and mouse peritoneal macrophages at $37^{\circ} \mathrm{C}$ (except where shown in Fig. 3). Cultures were fixed at the following times after infection: Figs I-3 (I h), 4-10 (I to $1.5 \mathrm{~h}$ ), II and I2 ( $24 \mathrm{~h}$ ), I3 (5 to 7 days), and 14 ( 5 days). Vertical blocks indicate means of three cultures, except in Fig. 14 where the number of determinations was one in experiment 247 and two in experiments 261 and 262 ; vertical lines indicate $\pm 2 \times$ s.E.M. Block numbers (in parentheses) indicate experimental conditions (see below); experiment numbers are shown beneath the block numbers.

Figs I, 4, 6 and II show percentages of macrophages with attached $T$. dionisii. Figs 2, 7 and I 2 show numbers of $T$. dionisii attached per 'receptive' macrophage (non-receptive cells, i.e. those with no attached trypanosome, omitted). Figs 3, 5, 8 and io show percentages of macrophages containing apparently viable $T$. dionisii (for control values for Fig. Io see blocks (9) in Fig. 8, but note that the vertical scale is expanded $\times$ Io in Fig. 10). Figs 9 and 13 show numbers of $T$. dionisii per infected macrophage (uninfected cells omitted). Fig. I4 shows percentages of extracellular trypomastigotes of $T$. dionisii in supernatant medium of infected macrophage cultures after 5 days.

Block numbers indicate: ( I) Live $T$. dionisii. (2) Dead $T$. dionisii. (3) Incubation temperature $4{ }^{\circ} \mathrm{C}$. (4) Incubation temperature $37^{\circ} \mathrm{C}$. (5) Macrophages treated with DMSO (I $\mu 1 \mathrm{ml}^{-1}$ ) alone for $\mathrm{I}$ to I 5 h. (6) Macrophages treated with cytochalasin B $\left(5 \mu \mathrm{g} \mathrm{ml}^{-1}\right)$ in DMSO $\left(1 \mu \mathrm{l} \mathrm{ml} l^{-1}\right)$ for $\mathbf{I}$ to $\mathrm{I} \cdot 5 \mathrm{~h}$. (7) Macrophages treated as in (6) followed by $30 \mathrm{~min}$ as in (5). (8) Macrophages treated with trypsin $\left(500 \mu \mathrm{g} \mathrm{ml}^{-1}\right)$ for $30 \mathrm{~min}$. (9) Macrophages not treated with trypsin. (10) Macrophages treated sequentially with cytochalasin B as in (6) followed by trypsin as in (8). (I I) Medium containing heatinactivated Wellcome calf serum no. I (WCSI; I0 \%, v/v). (I 2$)$ Medium containing heat-inactivated normal mouse plasma $(5 \%, \mathrm{v} / \mathrm{v})$ and WCSI $(5 \%)$. (13) Medium containing heat-inactivated immune mouse plasma $(5 \%, \mathrm{v} / \mathrm{v})$ and WCSI $(5 \%)$, except that concentrations were $\mathrm{I} \%$ mouse plasma plus $19 \%$ WCSI in experiment 225 and I \% mouse plasma plus $9 \%$ WCSI in experiments 229 and 233A (Fig. 13). 

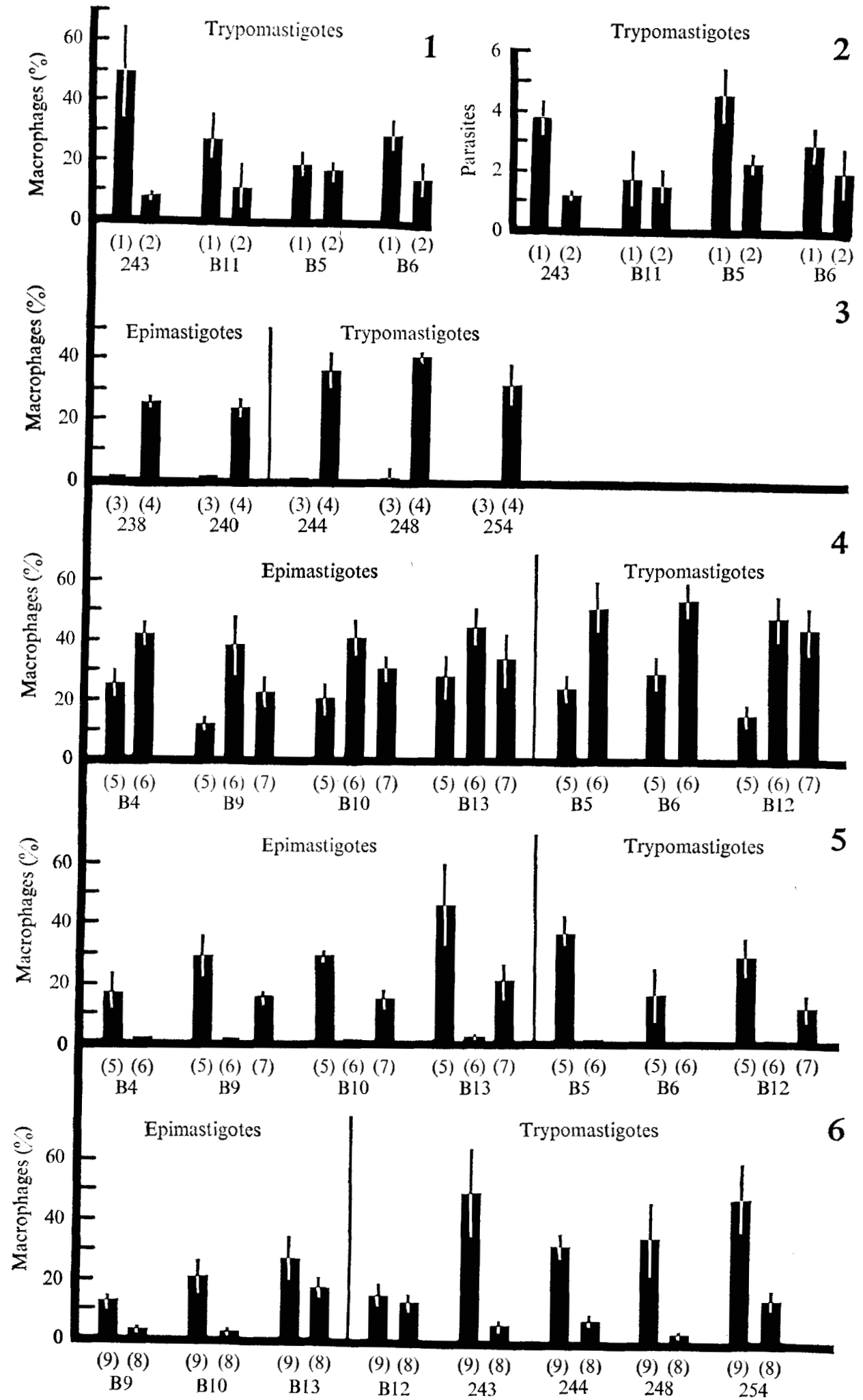

Figs $\mathrm{I}-6$. See legend on facing page. 
Immune plasma. Plasma were collected by cardiac puncture from male $\mathrm{P}(\mathrm{SD})$ mice anaesthetized with trichloroethylene B.P. (Trilene; ICI). Heparin was used as anticoagulant. Some mice were previously immunized with $T$. dionisii in Freund's Complete Adjuvant (FCA) or with FCA alone (Liston et al., 1977). Some plasma were inactivated by heating $\left(56^{\circ} \mathrm{C}, 30 \mathrm{~min}\right)$. The specific activity of the pooled inactivated mouse plasma was checked by the indirect fluorescent antibody test using goat anti-mouse immunoglobulin $\mathrm{G}$ conjugated with fluorescein isothiocyanate (Meloy Laboratories, C-403; 1:4 dilution) as stain with dried, methanol-fixed, washed $T$. dionisii $\mathrm{P}_{3}$ as antigen. Appropriate controls using normal mouse plasma or conjugate only were included.

Examination of cultures. After the appropriate time, cultures were washed, fixed and stained (Baker et al., 1972). Macrophages and intracellular or attached parasites were counted using a $\times$ Io square-grid ocular and $\times 50$ oil-immersion objective on a Wild M20 microscope. To avoid bias, slides were coded, the treatment each had received being unknown to the enumerator. Counts were made on Io microscope fields at sites distributed evenly over the area of each culture (a circle of about $\mathrm{I} \mathrm{cm}$ diameter) at predetermined settings of the mechanical stage. Triplicate cultures were examined and means with their standard errors (s.E.M.) were calculated. Living trypanosomes in supernatant medium were counted with a haemocytometer. Smears of supernatant were air-dried, fixed with methanol, stained with Giemsa's stain ( 1 : 1o in phosphate buffer, $\mathrm{pH} \mathrm{7.3)} \mathrm{and} \mathrm{code-numbered} \mathrm{for} \mathrm{determination} \mathrm{of} \mathrm{the} \mathrm{morphological} \mathrm{forms} \mathrm{present,} \mathrm{using} \times 15$ oculars and a $\times 50$ oil-immersion objective.

\section{RESULTS}

Comparison of attachment and endocytosis of living and dead trypanosomes. Results varied between experiments, but the only indications of reproducible differences were in the proportion of macrophages with attached trypomastigotes and in the number of trypomastigotes attached to each such cell, both of which tended to be slightly raised when live trypomastigotes were used, rather than those killed by heat (Figs I, 2). No indication of reproducible significant differences was detected when epimastigotes were used, or in the endocytosis of either trypomastigotes or epimastigotes.

Effect of macrophages from immune mice. Attachment of parasites to macrophages, and their uptake by these cells, occurred to a similar extent in cells harvested from normal mice and those from immune mice, comparisons being made in media containing normal mouse plasma, immune mouse plasma or calf serum only.

Effect of temperature. The proportions of macrophages with attached parasites were similar at 4 and $37^{\circ} \mathrm{C}$, as were the numbers of parasites attached to each such cell. The proportion of macrophages endocytosing parasites at $4{ }^{\circ} \mathrm{C}$ was reduced to $<\mathrm{I} \%$ in all except one experiment (no. 248), in which it averaged $I \cdot 7 \%$ (S.E.M. $2 \cdot 3$ ) (Fig. 3); the number of endocytosed parasites per cell rarely exceeded $\mathrm{I}$.

Effect of complement. Six experiments revealed no significant difference in the extent of attachment or ingestion of epimastigotes or trypomastigotes, or the proportions of macrophages with attached or endocytosed parasites, whether or not the parasites had been pretreated with reconstituted guinea-pig serum (as a source of complement) or similar serum which had been heat-inactivated.

Effect of cytochalasin B. Treatment of cultures with cytochalasin B approximately doubled the proportion of macrophages with attached parasites (Fig. 4); the numbers attached per individual cell were not affected. It also reduced the proportion of macrophages with endocytosed parasites to $<_{\mathrm{I}} \%$ in all but one experiment $\left(\mathrm{BI}_{\mathrm{I}} 3\right.$; mean $2.4 \%$, S.E.M. 0.84 ) and to zero in one (B6) (Fig. 5). Results were similar whether epimastigotes or trypomastigotes were used, and whether they were alive or heat-killed, the reduction being slightly less with the latter; the number of endocytosed parasites per infected cell was reduced to $\mathrm{I}$ in all but one experiment (BI3; mean I.05, S.E.M. 0.05). When the drug treatment was followed by exposure to drug-free medium before fixation, both effects (on attachment and ingestion) were partially reversed (Figs 4,5 ).

Effect of trypsin. Treatment of macrophages with trypsin before exposing them to live epimastigotes or trypomastigotes reduced the percentages of macrophages with attached and ingested parasites (Figs 6,8) and also the numbers of attached and ingested parasites per cell 


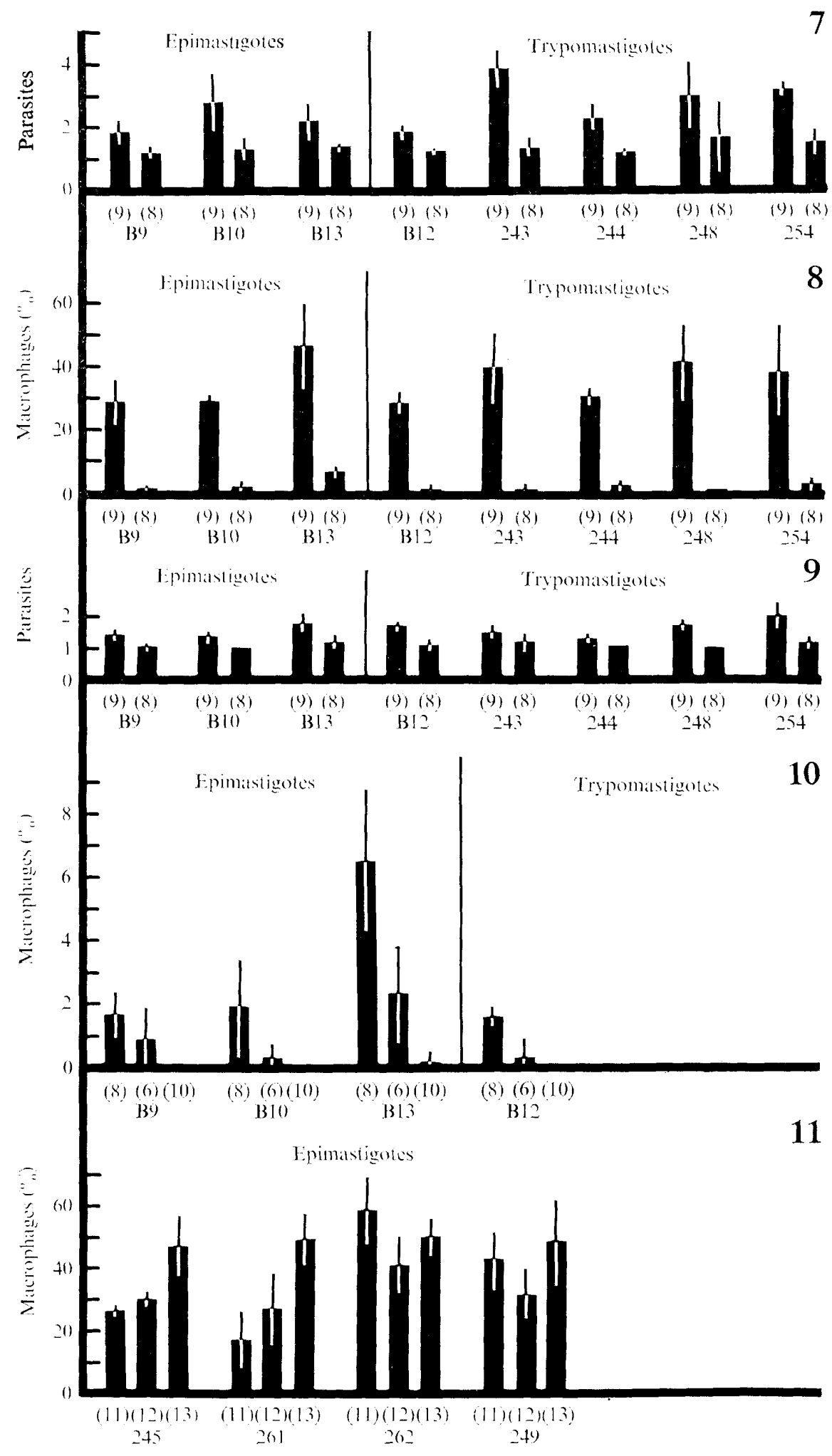

Figs 7-II. See legend on p. 80. 

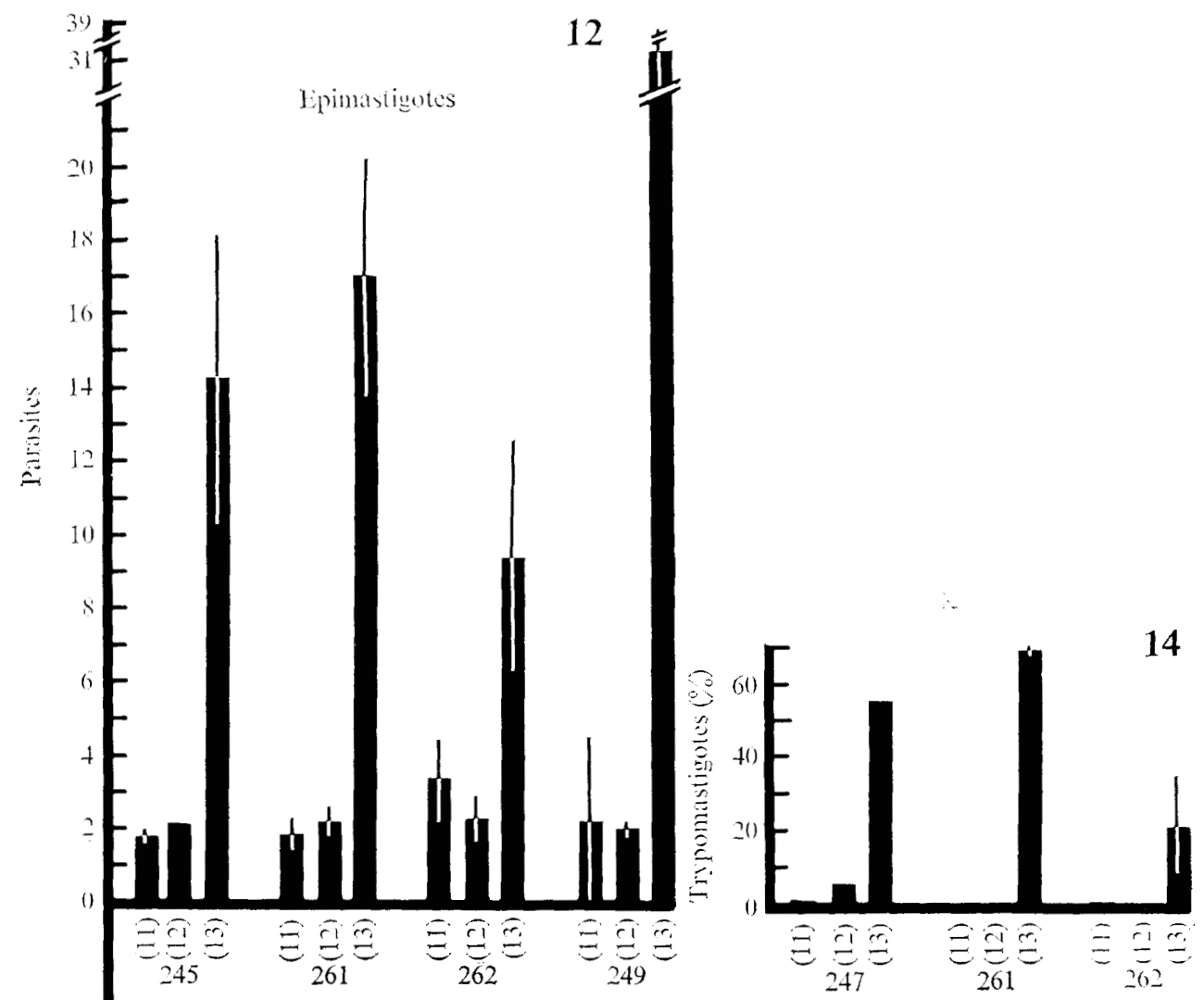

Epimastigoles

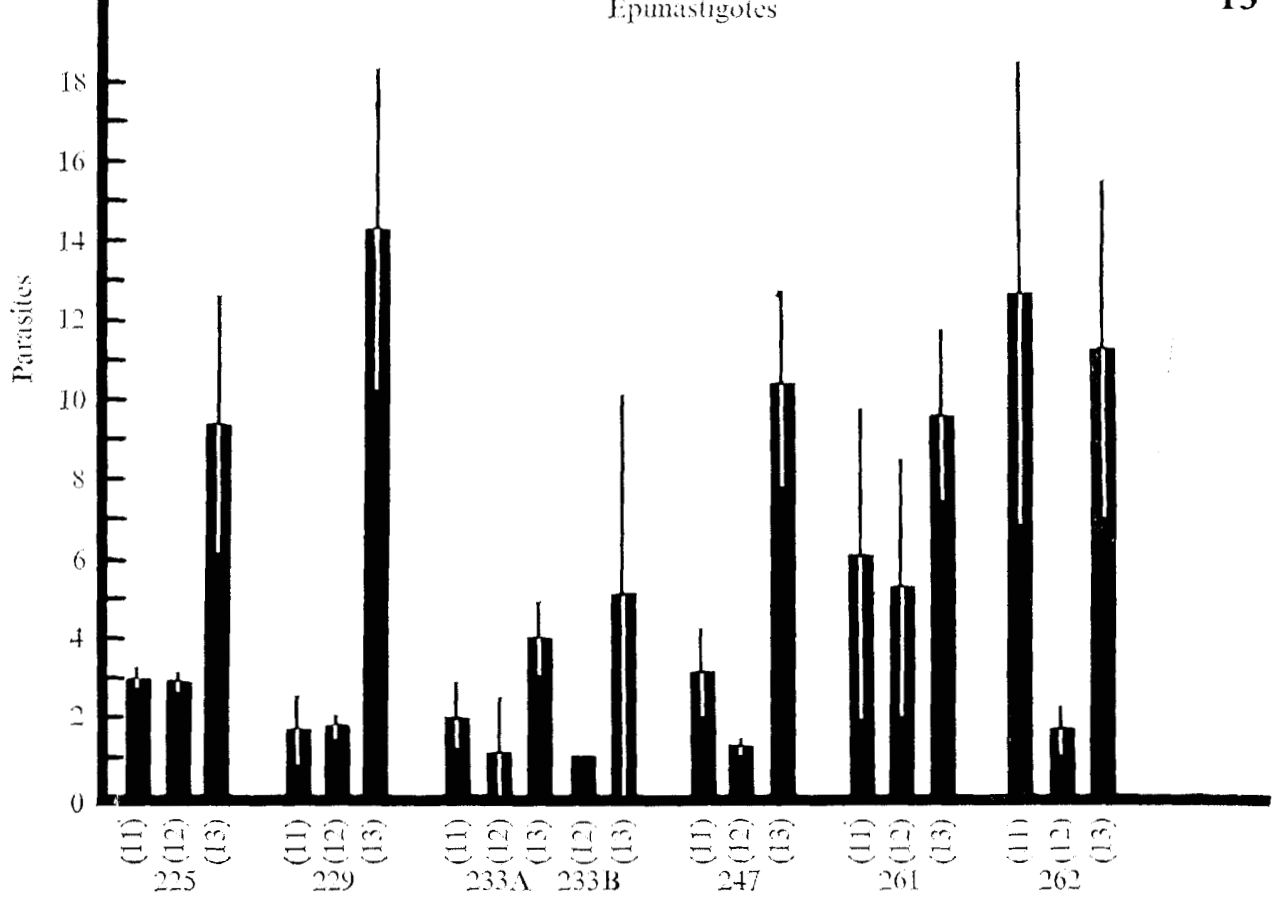

Figs 12-14. See legend on p. 80. 
(Figs 7,9 ); ingestion rates were particularly reduced, to about $10 \%$ or less of the values obtained in control cultures. Similar effects were seen when dead parasites were used.

Effect of trypsin and cytochalasin B together. Treatment of macrophages with cytochalasin $B$ and trypsin in succession did not affect the attachment of parasites to macrophages any more than the application of trypsin alone. It did, however, further reduce the proportion of macrophages ingesting parasites - to zero in three of four experiments and to a mean value of $0.14 \%$ (S.E.M. 0.14 ) in the fourth (Fig. IO); in fact, only a single macrophage apparently containing a single parasite was seen in this experiment (BI3).

Effect of immune plasma. Trypanosoma dionisii treated with pooled plasma from mice immunized with the same stock (IMP) and fluorescein-conjugated anti-mouse immunoglobulin $G$ fluoresced to a titre of $\mathrm{x} \cdot 64$; no control preparation showed more than a trace of fluorescence. In cultures of macrophages and trypanosomes, inclusion in the medium of inactivated IMP $[5 \%(\mathrm{v} / \mathrm{v})$ plus $5 \%(\mathrm{v} / \mathrm{v})$ calf serum] resulted, in two out of four experiments, in a significantly increased proportion of macrophages with attached parasites after $24 \mathrm{~h}$ incubation (Fig. II); this also occurred with non-inactivated plasma. The effect was not apparent after $\mathrm{I} 20 \mathrm{~h}$. Inactivated IMP always resulted in an increase in the number of parasites attached to each cell at $24 \mathrm{~h}$ (Fig. I2) and, even more so, at I $20 \mathrm{~h}$; non-inactivated IMP did not. Plasma from non-immunized mice (inactivated or not) had little if any stimulatory effect on either property at $24 \mathrm{~h}$ (Figs I I, I2) and none at all at I $20 \mathrm{~h}$. No difference resulted from the use of macrophages collected from mice immunized with either P3 and FCA or FCA alone. Inactivated IMP at I or $5 \%(\mathrm{v} / \mathrm{v})$ did not affect the uptake of parasites by macrophages $24 \mathrm{~h}$ after addition of trypanosomes to the cultures, but in all of seven experiments the number of parasites per infected cell was markedly increased 5 to 7 days after infection, compared with cultures in medium containing normal mouse plasma, or (in six of the seven experiments) in calf serum alone (Fig. 13). Infected macrophages in cultures with inactivated IMP contained many large multinucleate parasites (Fig. 15), which were seen rarely if at all in other cultures; large 'syncytial' masses of multinucleate extracellular parasites, often vacuolated, were also seen. No extracellular parasite and only rare intracellular forms were seen by the fifth day after infection in cultures containing noninactivated IMP.

Morphogenesis of parasites. In all of three experiments in which the parasite inoculum contained $>95 \%$ epimastigotes from I-day-old L4NHS cultures, the inclusion in the medium of $5 \%(\mathrm{v} / \mathrm{v})$ IMP (heat inactivated), plus $5 \%$ calf serum, induced the appearance in the supernatant medium of a high proportion ( 20 to $70 \%$ ) of trypomastigotes by the fifth day after infection (Fig. I4). In control cultures, containing either $5 \%$ inactivated normal mouse plasma plus $5 \%$ calf serum or $10 \%$ calf serum alone, the percentage of trypomastigotes never exceeded 6 and was usually I or less. The characteristic long thin trypomastigotes which develop in liquid medium at $28^{\circ} \mathrm{C}$ (Baker et al., I972) were usually only a minority of those seen in cultures containing IMP (Fig. I6), though in one experiment they formed about $50 \%$ of the population of trypomastigotes. The predominant forms in cultures not containing IMP, and most of the forms other than trypomastigotes in cultures with IMP, were epimastigotes. This effect was not seen $24 \mathrm{~h}$ after infection of the cultures. At 5 days some macrophages contained what appeared to be parasites transforming into small trypomastigotes (Fig. 17). None of the mouse plasma supported extracellular growth of trypanosomes as well as calf serum did; IMP was less satisfactory than that from normal mice (Table I).

\section{DISCUSSION}

These results indicate firstly that, in our system, uptake of the parasites by macrophages is mediated entirely (or almost so) by phagocytosis and not by active penetration by the parasites (epimastigotes or trypomastigotes); dead or living parasites are ingested to a similar extent, and cytochalasin B (known to interfere with phagocytosis) almost completely 

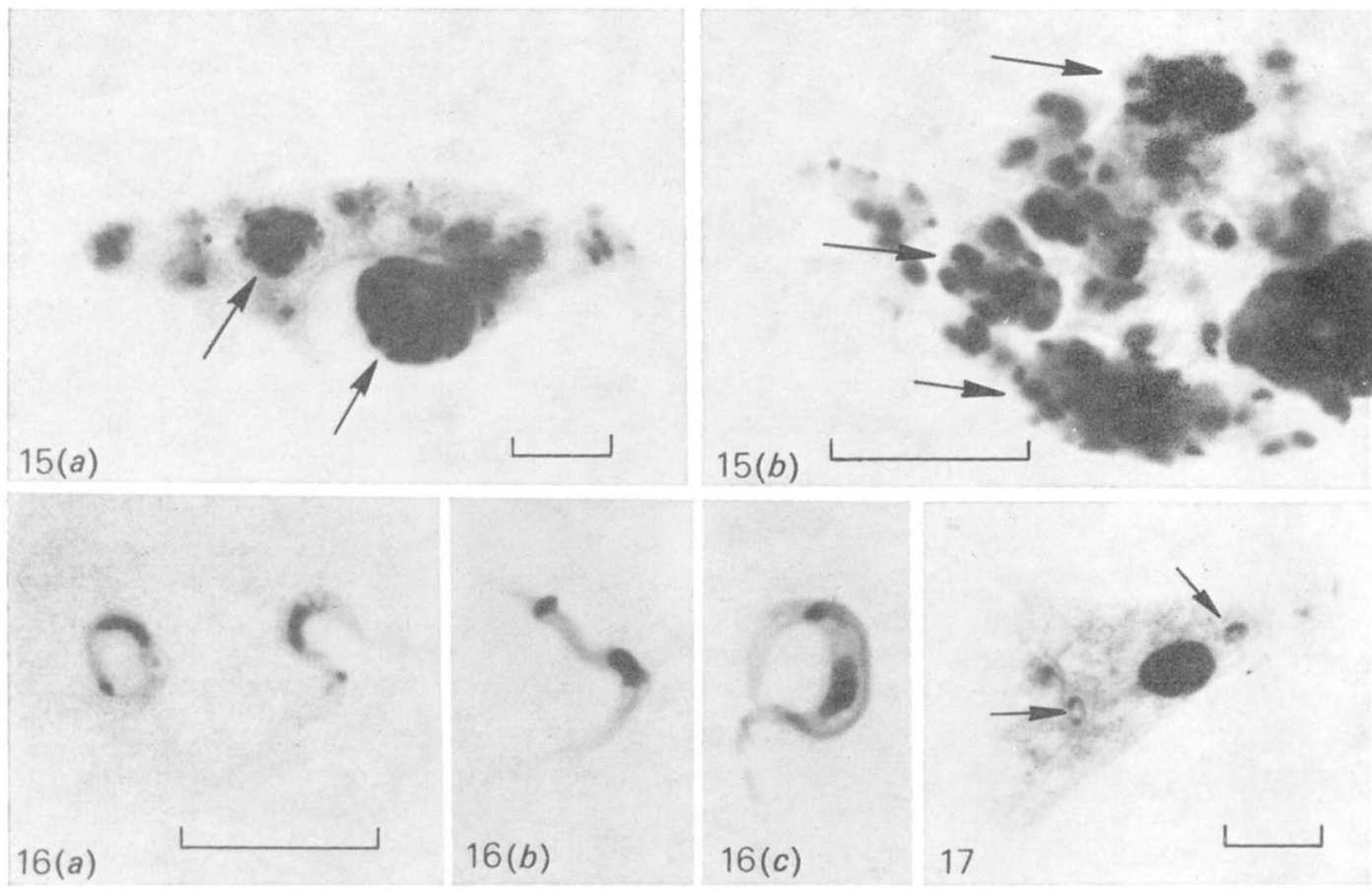

$16(a)$ $16(b)$

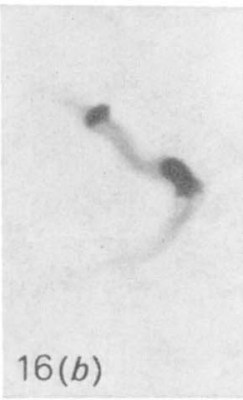

All bar markers represent $10 \mu \mathrm{m}$.

Fig. 15. (a) Photomicrograph of a mouse peritoneal macrophage in a 5 -day-old culture $(5 \%$ heatinactivated immune mouse plasma, $37^{\circ} \mathrm{C}$ ) containing multinucleate stages (arrowed) of $T$. dionisii (clone 3 of stock P3); Giemsa's stain. (b) Part of a similar cell at higher magnification.

Fig. 16. (a-c) Photomicrographs of extracellular trypomastigotes of $T$. dionisii (clone 3 of stock P3) in the supernatant medium of a culture as in Fig. I5; Giemsa's stain.

Fig. 17. Photomicrograph of a mouse peritoneal macrophage in a culture as in Fig. I 5 but fixed after 6 days, containing $T$. dionisii (clone 3 of stock P3) apparently differentiating into trypomastigotes (arrowed); Giemsa's stain.

Table I. Numbers of parasites in supernatant medium of macrophage cultures containing different plasma or sera $\left(37^{\circ} \mathrm{C}\right)$

Counts are expressed as means of three cultures $\pm 2 \times$ S.E.M.

\begin{tabular}{|c|c|c|c|c|c|c|}
\hline \multirow{2}{*}{$\begin{array}{l}\text { Expt } \\
\text { no. }\end{array}$} & \multirow{2}{*}{$\begin{array}{l}\text { Time after } \\
\text { inoculation } \\
\text { (days) }\end{array}$} & \multicolumn{5}{|c|}{$10^{-5} \times$ No. of parasites $\mathrm{ml}^{-1}$} \\
\hline & & NMP & NMPi & IMP & IMPi & WCSI $_{I}$ \\
\hline 247 & 2 & $5 \cdot 5 \pm 2 \cdot 5$ & $9 \cdot 0 \pm 2 \cdot 5$ & $0.4 \pm 0.3$ & $0.2 \pm 0 . I$ & $17 \cdot 8 \pm 5$ \\
\hline $26 \mathrm{I}$ & I & $9 \cdot 8 \pm \mathbf{I} \cdot 2$ & $8 \cdot 3 \pm \mathrm{I} \cdot 3$ & $3.5 \pm 0.8$ & $0.03 \pm 0.07$ & $10 \cdot 6 \pm 2 \cdot I$ \\
\hline 262 & I & $9.0 \pm 0.5$ & $6.7 \pm 0.4$ & $2 \cdot 4 \pm x \cdot 6$ & $1.2 \pm 0.3$ & $\mathrm{I} 4 \cdot \mathrm{I} \pm \mathrm{I} \cdot 8$ \\
\hline
\end{tabular}

NMP, Normal mouse plasma; IMP, immune mouse plasma; i, heat inactivated; WCSI, Wellcome calf serum no. I.

inhibits entry, as it has been shown to do with T. cruzi (Nogueira \& Cohn, 1976). The apparently only partial reversal of the effect when cells were subsequently incubated in drugfree medium can be explained by the fact that only $30 \mathrm{~min}$ was then available for cells to ingest already attached parasites before the cultures were fixed, compared with $\mathrm{I} \cdot 5$ to $2 \mathrm{~h}$ in cultures never exposed to the drug (see Methods). There appears to be a difference in the mode of entry of $T$. cruzi into host cells in vitro, depending on the type of cell studied; workers using non-phagocytic host cells reported active penetration (Dvorak \& Hyde, I973; Kongtong \& Inoki, 1975; Kreier, Al-Abassy \& Seed, 1976; Sooksri \& Inoki, 1972; 
Tanowitz et al., 1975) while most of those using macrophages observed phagocytosis only (Milder, Kloetzel \& Deane, 1973; Tanowitz et al., 1975; Nogueira \& Cohn, 1976), as we did. Dvorak \& Schmuñis (I972), however, reported active penetration into macrophages.

Secondly, prior attachment of the parasites to the macrophage surface is necessary for their uptake: when this is inhibited by trypsin treatment of the macrophages, virtually no endocytosis occurs. Some attachment after treatment with trypsin is recorded in Figs 6 and 7; this may be due in part to chance juxtaposition of trypanosomes and cells surviving the prefixation wash. We believe that the apparent increased extent of attachment to cells treated with cytochalasin B results from the fact that attached parasites were not being removed by subsequent phagocytosis.

Thirdly, some conclusions may be drawn regarding the identity of the receptors on the macrophage surface membrane concerned in this attachment. Adhesion to macrophages is mediated by one or more of three types of receptors on the macrophage surface - those which bind the Fc portion of antibody molecules, those binding the $\mathrm{C}^{\prime} 3 \mathrm{~b}$ component of complement and a third non-specific group not requiring either kind of linking molecule (Gordon \& Cohn, 1973; Griffin, Bianco \& Silverstein, 1975). Adherence to the complement receptors is temperature dependent, and only the immunoglobulin $\mathrm{Fc}$ receptors resist digestion by trypsin (Gordon \& Cohn, I973), though Unkeless (I977) has reported a subtype of $F c$ receptor which is sensitive to trypsin. Our results indicate that most if not all of the adhesion to macrophages of $T$. dionisii epimastigotes and trypomastigotes occurring in cultures containing non-immune sera or plasma was mediated by non-specific receptors, independent of antibody or complement. However, the increased adhesion in the presence of specific mouse immune plasma doubtless involved $\mathrm{Fc}$ receptors also. We did not observe this enhancement in cultures containing non-inactivated immune plasma, and in this respect our results differed from those of Kloetzel \& Deane (1970), with T. cruzi in vitro. However, the latter authors used haematozoic trypomastigotes, rat peritoneal macrophages, heterologous (equine) serum and rat complement and examined cultures after $30^{\circ} \mathrm{min}$; any or all of these features might account for the difference, though perhaps the last is the most likely to do so; in our experiments more time $(24 \mathrm{~h})$ was available for the manifestation of complement-mediated immune lysis.

Fourthly, the enhancement of attachment by immune plasma did not apparently lead to increased endocytosis of the parasites, at least within $24 \mathrm{~h}$. The increased number of intracellular parasites seen after $\mathrm{I} 20 \mathrm{~h}$ in cultures containing inactivated IMP probably resulted from increased intracellular replication, since large multinucleate (and multikinetoplastate) parasites apparently undergoing multiple fission were common within the macrophages; these forms may have resulted from a direct effect of antibody on the parasite initiated before the latter entered the macrophage, either via the parasite's surface membrane or via antiserum endocytosed by the parasite. Specific antiserum influences the development of $T$. cruzi and Leishmania tarentolae in cell-free cultures at $26^{\circ} \mathrm{C}$, resulting in the appearance of large agglutinated parasite masses (Adler, 1958; Strauss, 197I); similar extracellular forms were seen in our cultures containing inactivated IMP, but - in contrast to the intracellular forms - they were usually vacuolated and appeared degenerate. Hoff (I975) found that macrophages from mice chronically infected with $T$. cruzi did not permit intracellular replication of ingested parasites during $72 \mathrm{~h}$ in vitro, as macrophages from uninfected mice did. Immune macrophages pretreated with inactivated normal mouse sera ingested less than half as many parasites as did normal macrophages pretreated with immune serum. These experiments differed from ours as only macrophages were exposed to the sera, whereas in our work macrophages and parasites were exposed; also, our immunization procedure was artificial.

Fifthly, inactivated IMP also appeared to stimulate redifferentiation of $T$. dionisii into trypomastigotes in cell cultures. Baker et al. (1972) reported this within macrophages and HeLa cells 7 days or more after infection of cultures, but not to the extent seen in the 
present study after 5 days in medium containing IMP. The observation in these cultures of macrophages containing parasites apparently undergoing morphogenesis to trypomastigotes (Fig. 17; cf. Plate 2, Figs 8-I0 of Baker et al., 1972) suggested that at least some of this redifferentiation into trypomastigotes occurred intracellularly, as did the apparent absence of extracellular forms transitional between epimastigotes and the small trypomastigotes. Adler (1958) reported increased production of trypomastigotes at $26{ }^{\circ} \mathrm{C}$ in cell-free cultures of $T$. cruzi containing specific antiserum.

Although one cannot directly relate events occurring in vitro with $T$. dionisii to those occurring in vivo with $T$. cruzi, it is possible that, if homologous humoral antibody has a similar stimulating effect on intracellular replication and morphogenesis of $T$. cruzi in vivo, this might be important in the pathogenesis of Chagas's disease. Although immune plasma with active complement destroyed extra- and intracellular parasites within 5 days in our cultures, and complement-dependent immune lysis of extracellular $T$. cruzi occurs in mice (Budzko, Pizzimenti \& Kierszenbaum, 1975), complement depletion, shown in rats infected with $T$. lewisi (Jarvinen \& Dalmasso, 1976), might possibly occur in cases of chronic $T$. cruzi infection to an extent permitting any stimulatory effect of antiserum to supervene.

We thank Miss L. F. Selden for much help. This work was partially supported by a grant from the Ministry of Overseas Development.

\section{REFERENCES}

ADLER, S. (1958). The action of specific serum on a strain of Trypanosoma cruzi. Annals of Tropical Medicine and Parasitology 52, 282-301.

BAKER, J. R. (1976). Species of the subgenus Schizotrypanum other than Trypanosoma cruzi and their potential usefulness in the laboratory. Transactions of the Royal Society of Tropical Medicine and Hygiene 70, 126-I 27.

Baker, J. R., Green, S. M., Chaloner, L. A. \& GABORAK, M. (1972). Trypanosoma (Schizotrypanum) dionisii of Pipistrellus pipistrellus (Chiroptera): intra- and extra-cellular development in vitro. Parasitology 65, 25 $\mathrm{I}-263$.

BAKer, J. R., Liston, A. J. \& SElden, L. F. (1976). Trypomastigote dimorphism and satellite deoxyribonucleic acid in a clone of Trypanosoma (Schizotrypanum) dionisii. Journal of General Microbiology 97, I I 3-I I 5.

Budzko, D. B., Pizzimenti, M. C. \& Kierszenbaum, F. (I975). Effects of complement depletion in experimental Chagas' disease: immune Jysis of virulent blood forms of Trypanosoma cruzi. Infection and Immunity II, 86-9I.

Dvorak, J. A. \& HYDE, T. P. (1973). Trypanosoma cruzi: interaction with vertebrate cells in vitro. J. Individual reactions at the cellular and subcellular level. Experimental Parasitology 34, 268-283.

Dvorak, J. A. \& SchmuñIs, G. A. (1972). Trypanosoma cruzi: interaction with mouse peritoneal macrophages. Experimental Parasitology 32, 289-300.

Gordon, S. \& CoHn, Z. A. (1973). The macrophage. International Review of Cytology 36, I 7 I-2 I4.

Griffin, F. M., Bianco, C. \& Silverstein, S. C. (1975). Characterization of the macrophage receptor for complement and demonstration of its functional independence from the receptor for the Fc portion of immunoglobulin G. Journal of Experimental Medicine 141, I269-1277.

Hoff, R. (1975). Killing in vitro of Trypanosoma cruzi by macrophages from mice immunized with $T$. cruzi or BCG, and absence of cross-immunity on challenge in vivo. Journal of Experimental Medicine 142, 299-3I I.

Jarvinen, J. A. \& Dalmasso, A. P. (I976). Complement in experimental Trypanosoma lewisi infections of rats. Infection and Immunity 14, 894-902.

Kloetzel, J. \& Deane, M. P. (I970). Adherence of sensitized trypanosomes to peritoneal cells. Revista do Instituto de medicina tropical de São Paulo I2, 383-387.

Kongtong, P. \& INOKi, S. (I975). Scanning electron microscopic studies on penetration of Trypanosoma cruzi into fibroblast cells. Japanese Journal of Parasitology 24, 284-293.

Kreier, J. P., Al-Abassy, S. M. \& Seed, T. M. (1976). Trypanosoma cruzi: observations on entry, development, release and ultrastructure of parasites grown in cell cultures. Ohio Journal of Science 76, 243-253.

Liston, A. J. (1975). Trypanosoma (Schizotrypanum) dionisii in macrophage cultures. I. Preliminary observations on entry into cells. Parasitology $\mathbf{7} \mathbf{x}$, xviii.

Liston, A. J. \& BAKER, J. R. (I977). Trypanosoma dionisii: attachment and entry to mouse peritoneal macrophages in vitro and the involvement of membrane receptors. Journal of Protozoology (in the Press). [Abstract]

Liston, A. J., Baker, J. R. \& Selden, L. F. (1977). Specific delayed-type hypersensitivity footpad response in mice artificially immunized with two Trypanosoma (Schizotrypanum) species. Journal of General Microbiology 98, 6r5-617. 
Milder, R. V., Kloetzel, J. \& Deane, M. P. Strauss, P. R. (1971). The effect of homologous (1973). Observation on the interaction of peritoneal macrophages with Trypanosoma cruzi. I. Initial phase of the relationship with blood stream and culture forms in vitro. Revista do Instituto de medicina tropical de São Paulo I5, 386-392.

Nogueira, N. \& CoHN, Z. (1976). Trypanosoma cruzi: mechanism of entry and intracellular fate in mammalian cells. Journal of Experimental Medicine 143, I402-1420.

SoOKSRI, V. \& INOKI, S. (I972). Electron microscopic studies on penetration and development of Trypanosoma cruzi in HeLa cells. Biken Journal I5, 179-I9I. rabbit antiserum on the growth of Leishmania tarentolae-a fine structure study. Journal of Protozoology 18, I47-156.

Tanowitz, H., WitTNer, M., Kress, Y. \& Bloom, B. (1975). Studies of in vitro infection by Trypanosoma cruzi. I. Ultrastructural studies on the invasion of macrophages and L-cells. American Journal of Tropical Medicine 24, 25-33.

UNKELESS, J. C. (1977). The presence of two Fc receptors on mouse macrophages: evidence from a variant cell line and differential trypsin sensitivity. Journal of Experimental Medicine 145, 93I-947. 